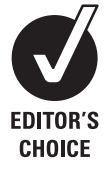

${ }^{1}$ Institute of Environmental Medicine, Karolinska Institutet, Stockholm, Sweden Institute for Medical Research, Jalan Pahang, Kuala Lumpur, Malaysia

${ }^{3}$ Unit of Clinical Immunology، Uppsala University, Uppsala, Sweden

${ }^{4}$ Rheumatology Unit, Department of Medicine, Karolinska Institutet at Karolinska Hospital, Solna, Stockholm, Sweden ${ }^{5}$ Department of Occupational and Environmental Medicine, Uppsala University Hospital, Uppsala, Sweden

\section{Correspondence to} Dr Patrik Stolt, Institute of Environmental Medicine, Karolinska Institutet, Box 210, S-171 77 Stockholm, Sweden; patrikstolt@swipnet.se

Accepted 19 November 2009

\title{
Silica exposure among male current smokers is associated with a high risk of developing ACPA- positive rheumatoid arthritis
}

\author{
Patrik Stolt, ${ }_{1}^{1}$ Abqariyah Yahya ${ }_{1}^{1,2}$ Camilla Bengtsson, ${ }^{1}$ Henrik Källberg, ${ }^{1}$ Johan \\ Rönnelid, ${ }^{3,4}$ Ingvar Lundberg, ${ }^{5}$ Lars Klareskog, ${ }^{4}$ Lars Alfredsson ${ }^{1}$; the EIRA Study Group
}

\begin{abstract}
Objective To study the association between silica exposure, separately as well as combined with smoking, and the risk of developing rheumatoid arthritis (RA) with or without the presence of antibodies against citrullinated peptide antigens (ACPA).
\end{abstract}

Methods This Swedish population based case-control study analysed 577 incident RA cases and 659 randomly selected controls, all men aged 18-70 years, included during May 1996 to May 2006. Self-reported silica exposure, defined as exposure to stone dust, rock drilling or stone crushing and cigarette smoking was registered. ACPA status among cases was analysed.

Results Silica-exposed subjects were found to have a moderately increased risk of ACPA-positive RA lodds ratio (OR) adjusted for age and residency $=1.67$ (95\% Cl 1.13 to 2.48), but not of ACPA-negative RA (OR=0.98 $(95 \%$ $\mathrm{Cl} 0.57$ to 1.66$))$, compared with subjects unexposed to silica. Subjects exposed to rock drilling were found to have a somewhat more markedly increased risk of ACPA-positive RA (OR=2.34 (95\% Cl 1.17 to 4.68)). A high risk of developing ACPA-positive RA was observed among silica-exposed current smokers $(\mathrm{OR}=7.36$ (95\% $\mathrm{Cl} 3.31$ to 16.38)), exceeding the risk expected from the separate effects of silica exposure and current smoking, indicating an interaction between these exposures (attributable proportion due to interaction $=0.60(95 \% \mathrm{Cl}$ 0.26 to 0.95$))$.

Conclusion Silica exposure combined with smoking among men is associated with an increased risk of developing ACPA-positive RA. These results suggest that different inhalation exposures may interact in the aetiology of ACPA-positive RA.

\section{INTRODUCTION}

The association between smoking and development of rheumatoid arthritis (RA) ${ }^{1-6}$ is the most recognised link between the environment and the aetiology of this disease and was subsequently found to be confined to the subset of RA defined by the presence of antibodies to citrullinated peptides (ACPA). ${ }^{6}$ Interaction between smoking and the most recognised, non-sex-linked, genetic risk factor of RA - that is, the HLA-DRB1 'shared epitope' (SE), ${ }^{7}$ for the risk of developing ACPA-positive RA, has been described. ${ }^{6-11}$

Exposure to crystalline silica is another welldefined inhalation exposure, reported, for example, from industries involving mining, construction, ceramics, glass, agriculture, but also from branches such as electronics. It is commonly occurring globally, although exposure levels in Western industries, in general, have decreased during recent decades. ${ }^{12-15}$ Silica exposure has been observed to be linked to RA and other immunologically mediated diseases, ${ }^{16-19}$ and our group found that it was associated with an about twofold increased risk of developing RA overall, also when smoking was considered as a potential confounder. ${ }^{19}$ In that study, silica-exposed ever-smokers were found to have an increased risk of RA, statistically significant for the rheumatoid factor-positive, but not the rheumatoid factor-negative, subset of the disease. The small number of silica-exposed never-smokers left the corresponding results for that category inconclusive. Results compatible with an interaction between silica exposure and smoking transpired, but were regarded with caution owing to the small number of silica-exposed never-smokers. ${ }^{19}$

No previous study available in PubMed, however, has described the link between silica exposure, separately or combined with smoking or SE, and the risk of developing RA of different ACPA status. This study aimed at investigating these issues, as they are of interest for an understanding of the mechanisms linking silica exposure, in particular, and air borne agents, in general, to the development of RA and for the discussions about preventive measures against the disease.

\section{MATERIALS AND METHODS}

This study is based on EIRA (Epidemiological Investigation of RA), which is a case-control study comprising the general population, aged 18-70 years, of a geographically defined part of Sweden. The present study analysed 577 male cases and 659 male controls included during May 1996 to May 2006, but none of the female study subjects because they were exposed to silica only rarely.

The study was approved by the regional committee on ethics at Karolinska Institutet, Stockholm, Sweden.

\section{Case definition and identification}

A case was defined as a person in the study base with newly developed RA, defined according to the American College of Rheumatology criteria. ${ }^{20}$ All potential cases were evaluated by a rheumatologist. Twenty-one units, including all public rheumatology units and almost all privately run units in the study area, reported cases. ${ }^{21}$ Initially, subjects with undifferentiated arthritis were also included, in order to investigate a broader spectrum of arthritis. These 57 subjects were excluded from this study. 


\section{Selection of controls}

The selection of controls aimed at achieving a control group with a distribution of exposures reflecting that of the study base, but with consideration taken of the age, gender and residency of the case group.

For each case, a control was randomly selected from the study base with consideration taken of age, gender and residency, using the national population register, which is continuously updated. If a control did not participate, a new control was selected using the same principles. In order to increase power, the male controls selected to match the subjects with undifferentiated arthritis were retained in the study, despite the exclusion of the corresponding case group.

\section{Data collection}

Exposure data were self-reported by subjects included in the study using a questionnaire. ${ }^{41922}$ Completed questionnaires were obtained from $95 \%$ of the case group and $81 \%$ of the controls.

\section{Exposures}

The questionnaire explores individual, demographic and environmental factors, including occupational exposures during different time periods. ${ }^{41922}$

The realisation of the first joint swelling was used as an estimate of disease onset for each case and the year of that first swelling was defined as the index year. The same index year was used for the corresponding control. Only exposure data up to the index year were analysed. Subjects exposed to rock drilling, stone crushing or stone dust during the index year or before, were classified as silica exposed.

Rock drilling and stone crushing have previously been found to be associated with a high degree of silica exposure. ${ }^{23-25}$ Doses of silica exposure were not estimated in this study, however, as no results from hygienic measurements were available.

Cigarette smokers were categorised as current smokers if they had regularly smoked during the index year, as ex-smokers if they had smoked before, but not during, the index year and as ever-smokers if they had smoked during or before the index year. People who had never smoked during or before the index year were defined as never-smokers.

\section{Potential confounders}

Age, residential area, social class, joint injury and physical work load were considered as potential confounders. Age was categorised into 10 strata. ${ }^{4} 1922$ The occupation during the index year was used as a marker for social class. ${ }^{22}$ Physical work load was classified using eight alternatives, ranging from 'not demanding at all' to 'very, very demanding'. Joint injury was defined as any joint injury requiring medical attention.

\section{Analyses of ACPA}

ACPA were identified and quantified with Immunoscan-RA Mark2 ELISA test (anti-CCP2 test). An antibody level >25 AU/ $\mathrm{ml}$ was regarded as ACPA positivity. ${ }^{626}$

\section{Genotyping}

Genotyping for SE alleles, defined as DRB1*01, *04 and *10 of the HLA-DRB1 gene, was conducted by SSP-PCR. ${ }^{27}$ People carrying one or two SE alleles were classified as having any SE alleles.

\section{Statistical analyses}

Silica-exposed subjects were compared with subjects unexposed to silica, and subjects with different combinations of silica- exposure status, smoking habits and SE status, were compared for the incidence of ACPA-positive RA, ACPA-negative RA, and $\mathrm{RA}$ overall, by calculating odds ratio (OR) with $95 \% \mathrm{CI}$ using unconditional regression analysis. Matched analyses using conditional regression analysis were also conducted, the results of which are not presented, as they generally agreed with those of the unmatched analyses, but had lower precision. Odds ratios were adjusted for potential confounding from age and residential area. Adjustment for social class, joint injury and physical work load was also conducted, but only marginally changed the estimates and was not retained in the final analyses. Adjustment for potential confounding from smoking was not conducted, as this was contraindicated by results suggesting an interaction between smoking and silica exposure.

Odds ratios were interpreted as relative risks as the study was population based and the controls were a random sample from the study base and as the participation proportion was high. ${ }^{28}$

The interactions between silica exposure and smoking and between silica exposure and SE, were analysed using departure from additivity of effects as criterion of interaction and were quantified by calculating 'attributable proportion (AP) due to interaction' with $95 \% \mathrm{CI}^{29-31} \mathrm{AP}$ is the proportion of the incidence among individuals exposed to two interacting risk factors that is attributable to the interaction itself (ie, reflecting their combined effect beyond the sum of their independent effects).

All analyses were performed using the Statistical Analysis System (SAS) version 9.1.32

\section{RESULTS}

\section{Characteristics of the study group}

In this study, 577 cases and 659 controls were analysed. The proportion of silica-exposed subjects was $14 \%$ among the cases and $10.5 \%$ among the controls. The proportion of ACPA-positive subjects was $67.5 \%$ among silica-exposed cases and $55 \%$ among cases unexposed to silica. The proportion of ever-smokers was $70 \%$ among silica-exposed cases, 60\% among cases unexposed to silica, $59 \%$ among silica-exposed controls and $49 \%$ among controls unexposed to silica.

\section{Silica exposure}

Silica-exposed subjects (80 cases, 69 controls) were found to have a moderately increased risk of developing ACPA-positive RA, with an OR adjusted for age and residency of $1.67(95 \% \mathrm{CI}$ 1.13 to 2.48 ), but no increased risk of developing ACPA-negative $\mathrm{RA}(\mathrm{OR}=0.98$ (95\% CI 0.57 to 1.66)), compared with subjects unexposed to silica (table 1).

Subjects exposed to rock drilling (26 cases, 17 controls), regarded as highly exposed to silica, were found to have a somewhat more marked increase in the risk of developing ACPA-positive RA (OR adjusted for age and residency=2.34 (95\% CI 1.17 to 4.68)), but no increased risk of developing ACPA-negative RA (OR=0.96 (95\% CI 0.34 to 2.67)), compared with subjects unexposed to silica (table 1).

\section{Cigarette smoking}

Among subjects unexposed to silica, an increased risk of ACPApositive RA was observed among ever-smokers $(\mathrm{OR}=2.53$ (95\% CI 1.72 to 3.72$)$ ), current smokers ( $\mathrm{OR}=2.78(95 \%$ CI 1.77 to 4.38$)$ ) and among ex-smokers ( $\mathrm{OR}=2.52(95 \%$ CI 1.63 to 3.89$)$ ), compared with never-smokers unexposed to silica (table 2). 


\section{Silica exposure and cigarette smoking combined}

Current cigarette smokers who were silica exposed were found to have a pronounced increase in the risk of ACPA-positive RA compared with never-smokers unexposed to silica $(\mathrm{OR}=7.36$ (95\% CI 3.31 to 16.38$)$ ) (table 2 ). The corresponding result was 2.78 (95\% CI 1.77 to 4.38$)$ for current cigarette smokers unexposed to silica and 1.15 (95\% CI 0.42 to 3.15) for never-smokers exposed to silica (table 2). The relative risk of ACPA-positive RA for current cigarette smokers exposed to silica thus exceeds the risk expected from the separate effects of silica exposure and current smoking, indicating an interaction between these exposures. The AP was estimated at 0.60 with a $95 \%$ CI of 0.26 to 0.95 , indicating that this interaction is statistically significant (table 3).

Current cigarette smokers with more than 20 pack-years who were silica exposed, were observed to have an even more markedly increased risk of ACPA-positive RA (OR=14.19 (95\% CI 5.32 to 37.84$)$ ), and a high $\mathrm{AP}(0.74$ (95\% CI 0.48 to 1.00$)$ ) (data not shown).

When current smoking was replaced with ever-smoking, the risk of ACPA-positive RA fell somewhat, but was still distinctly increased $(\mathrm{OR}=4.08$ (95\% CI 2.31 to 7.21$)$ ) (table 2), while the $\mathrm{AP}$ was reduced and no longer statistically significant $(\mathrm{AP}=0.34$

Table 1 Odds ratio (OR) with 95\% Cl of developing ACPA-positive RA, ACPA-negative RA and RA overall, respectively, among men exposed to stone dust, rock drilling, stone crushing and silica overall, respectively, compared with men unexposed to silica

\begin{tabular}{lllll}
\hline \multirow{2}{*}{ Exposure } & Category of RA & $\begin{array}{l}\text { Number of exposed } \\
\text { cases/exposed controls }\end{array}$ & $\mathbf{O R}^{*}$ & $\mathbf{9 5 \%} \mathbf{C l}$ \\
\hline Stone dust & ACPA-positive RA & $44 / 58$ & 1.60 & 1.04 to 2.44 \\
& ACPA-negative RA & $17 / 58$ & 1.02 & 0.57 to 1.82 \\
& RA overall & $67 / 58$ & 1.38 & 0.95 to 2.02 \\
Rock-drilling & ACPA-positive RA & $18 / 17$ & 2.34 & 1.17 to 4.68 \\
& ACPA-negative RA & $5 / 17$ & 0.96 & 0.34 to 2.67 \\
& RA overall & $26 / 17$ & 1.83 & 0.97 to 3.43 \\
Stone crushing & ACPA-positive RA & $11 / 13$ & 2.03 & 0.88 to 4.67 \\
& ACPA-negative RA & $5 / 13$ & 1.34 & 0.45 to 3.97 \\
\multirow{5}{*}{ Silica overall } & ACPA-positive RA & $54 / 69$ & 1.62 & 0.77 to 3.43 \\
& RA overall & $17 / 13$ & 1.67 & 1.13 to 2.48 \\
& ACPA-negative RA & $20 / 69$ & 0.98 & 0.57 to 1.66 \\
& RA overall & $80 / 69$ & 1.39 & 0.98 to 1.96
\end{tabular}

${ }^{*} \mathrm{OR}$ adjusted for the potential confounding from age and residential area.

ACPA, antibodies against citrullinated peptide antigens; RA, rheumatoid arthritis.
(95\% CI -0.09 to 0.77$)$ ) (table 3). No indication of an interaction between ex-smoking and silica exposure transpired ( $\mathrm{AP}=0.02$ (95\% CI -0.77 to 0.81$)$ ) (table 3 ).

\section{Silica exposure and SE combined}

Silica-exposed subjects carrying any SE allele were observed to have increased risk of ACPA-positive RA, compared with subjects unexposed to silica without SE alleles, $\mathrm{OR}=11.39$ (95\% CI 5.10 to 22.07 ). The corresponding result was 7.86 (95\% CI 5.10 to 12.12 ) for subjects unexposed to silica carrying any SE allele and 2.51 (95\% CI 0.97 to 6.49) for silicaexposed subjects without SE alleles (table 4). The AP, however, remained inconclusive $(0.18(-0.33$ to 0.68$))$.

\section{DISCUSSION}

The risk of developing ACPA-positive RA was observed to be just above 1.5-fold increased among subjects exposed to silica overall and almost 2.5-fold increased among subjects exposed to rock drilling; neither group was found to have any increase in the risk of developing ACPA-negative RA, compared with subjects unexposed to silica (table 1). Silica-exposed current smokers were observed to have a more than sevenfold increase in the risk of ACPA-positive RA, exceeding the risk expected from the separate effects of silica exposure and smoking, suggesting that an interaction between these exposures contributes to development of ACPA-positive RA.

As an interaction between smoking and SE for the risk of ACPApositive RA was previously observed, ${ }^{6-11}$ we investigated the potential of an analogous interaction between silica exposure and $\mathrm{SE}$. The result of this analysis (AP $=0.18(95 \% \mathrm{CI}-0.33$ to $0.68)$ ), however, remained inconclusive owing to limited power, although it may be regarded as compatible with a slight tendency towards an interaction. The pattern was similar when the analysis was restricted to never-smokers.

This study is, to our knowledge, the first to observe that the association between silica exposure and the risk of developing RA is combined with ACPA positivity and extends thereby previously presented results. ${ }^{19}$ Furthermore, the combined effect of silica exposure and cigarette smoking, described in this study, is the first observation in which two environmental exposures appear to interact synergistically as susceptibility factors for ACPA-positive RA.

Table 2 Odds ratio (OR) with 95\% Cl of developing ACPA-positive RA, ACPA-negative RA and RA overall, respectively, among men with different combinations of silica exposure status and cigarette smoking, compared with men who were unexposed to silica and never-smokers

\begin{tabular}{|c|c|c|c|c|c|c|c|}
\hline \multirow[b]{2}{*}{ Smoking category } & \multirow[b]{2}{*}{ Category of RA } & \multicolumn{3}{|c|}{ Subjects unexposed to silica } & \multicolumn{3}{|c|}{ Subjects exposed to silica } \\
\hline & & $\begin{array}{l}\text { Number of } \\
\text { cases/controls }\end{array}$ & OR* & $95 \% \mathrm{Cl}$ & $\begin{array}{l}\text { Number of } \\
\text { cases/controls }\end{array}$ & $\mathbf{O R} *$ & $95 \% \mathrm{Cl}$ \\
\hline \multirow[t]{3}{*}{ Never-smokers } & ACPA-positive RA & $57 / 193$ & 1 & - & $6 / 17$ & 1.15 & 0.42 to 3.15 \\
\hline & ACPA-negative RA & $54 / 193$ & 1 & - & $4 / 17$ & 0.85 & 0.26 to 2.75 \\
\hline & RA overall & $25 / 193$ & 1 & - & $10 / 17$ & 0.86 & 0.37 to 1.98 \\
\hline \multirow[t]{3}{*}{ Ever-smokers } & ACPA-positive RA & $176 / 284$ & 2.53 & 1.72 to 3.72 & $38 / 41$ & 4.08 & 2.31 to 7.21 \\
\hline & ACPA-negative RA & $101 / 284$ & 1.23 & 0.83 to 1.84 & $13 / 41$ & 1.16 & 0.56 to 2.39 \\
\hline & RA overall & $297 / 284$ & 1.69 & 1.26 to 2.27 & $56 / 41$ & 2.35 & 1.46 to 3.80 \\
\hline \multirow[t]{3}{*}{ Ex-smokers } & ACPA-positive RA & $99 / 174$ & 2.52 & 1.63 to 3.89 & $17 / 28$ & 2.84 & 1.39 to 5.84 \\
\hline & ACPA-negative RA & $57 / 174$ & 1.03 & 0.65 to 1.62 & $9 / 28$ & 1.05 & 0.45 to 2.46 \\
\hline & RA overall & $171 / 174$ & 1.58 & 1.14 to 2.20 & $28 / 28$ & 1.71 & 0.94 to 3.08 \\
\hline \multirow[t]{3}{*}{ Current smokers } & ACPA-positive RA & $77 / 110$ & 2.78 & 1.77 to 4.38 & $21 / 13$ & 7.36 & 3.31 to 16.38 \\
\hline & ACPA-negative RA & $44 / 110$ & 1.43 & 0.88 to 2.34 & $4 / 13$ & 1.16 & 0.35 to 3.87 \\
\hline & RA overall & $126 / 110$ & 1.85 & 1.30 to 2.65 & $28 / 13$ & 3.64 & 1.78 to 7.46 \\
\hline
\end{tabular}

${ }^{*} \mathrm{OR}$ adjusted for the potential confounding from age and residential area.

ACPA, antibodies against citrullinated peptide antigens; RA, rheumatoid arthritis. 
The interaction between silica exposure and smoking and between silica exposure and SE was analysed using departure from additivity of effects as the criterion of interaction. This was described as the most appropriate approach for identifying 'biological interactions' by Rothman et al, ${ }^{29}$ who introduced the 'pie model' to explain risk in which two risk factors are either independent (ie, no pathway to disease requires involvement of both) or have biological interaction (ie, at least one pathway towards disease requires the involvement of both). He demonstrated algebraically, based on disease rates connected to the pie model that independent risk factors adhere to an additive model and that biological interaction results in departure from additivity of the disease rates. ${ }^{30} 31$ Therefore, the empirical criterion when assessing biological interaction is based on whether or not disease rates are additive. This criterion stems from a basic, but general, definition of biological interaction which is highly relevant for the search of disease mechanisms. The product term in a logistic regression model does, in general, not allow such a specific biological interpretation.

In the primary assessment of the combined effect of silica exposure and smoking, ever exposure to silica and current smoking was analysed. The reason for this is that people ever exposed to crystalline silica may be regarded as potentially exposed to silica particles indefinitely as it has been found previously that silica particles may remain in lung tissues permanently, ${ }^{33}$ whereas cigarette smoke contains numerous components with different characteristics ${ }^{34}$ and the impact of smoking on the risk of RA has been found to eventually disappear after smoking cessation. ${ }^{14}$

The conclusiveness of the results for the association between silica exposure and ACPA-positive RA is weakened by the lack of statistical significance in the separate results for exposure to stone crushing and the borderline statistical significance for exposure to stone dust (table 1). Furthermore, the limited number of

Table 3 Attributable proportion (AP) due to interaction between evercigarette smoking, ex-cigarette smoking and current cigarette smoking, respectively, and silica exposure, associated with the risk of developing ACPA-positive RA and RA overall, respectively, with $95 \% \mathrm{CI}$

\begin{tabular}{lllll}
\hline & & \multicolumn{3}{l}{ Subjects exposed to silica } \\
\cline { 3 - 5 } Smoking category & Category of RA & $\begin{array}{l}\text { Number of } \\
\text { cases/controls }\end{array}$ & AP & $\mathbf{9 5 \%} \mathbf{~ C l}$ \\
\hline Ever-cigarette smoking & ACPA-positive RA & $38 / 41$ & 0.34 & -0.09 to 0.77 \\
& RA overall & $56 / 41$ & 0.34 & -0.09 to 0.77 \\
Ex-cigarette smoking & ACPA-positive RA & $17 / 28$ & 0.02 & -0.77 to 0.81 \\
& RA overall & $28 / 28$ & 0.14 & -0.53 to 0.81 \\
Current cigarette & ACPA-positive RA & $21 / 13$ & 0.60 & 0.26 to 0.95 \\
smoking & RA overall & $28 / 13$ & 0.52 & 0.12 to 0.93 \\
\hline
\end{tabular}

ACPA, antibodies against citrullinated peptide antigens; RA, rheumatoid arthritis. silica-exposed never-smokers reduces the possibility of drawing conclusions about the association between silica exposure and ACPA-positive RA in the absence of smoking (table 2).

The limited number of silica-exposed never-smokers (table 2), as well as the possibility of unknown confounders, also suggests caution in interpretation of the result for the combined effect of silica exposure and smoking (table 3).

The retrospective collection of exposure data in this study may introduce a risk of recall bias and overestimation of the association between silica exposure and RA. Such a bias, however, would most probably not have differed between the ACPA-positive and the ACPA-negative subgroup.

The risk of selection bias due to non-response was reduced by the high participation proportion (95\% among cases, $81 \%$ among controls) of this study and by results in a previous report from EIRA, in which non-participation was observed to have a minor impact on the estimated relative risks regarding education and occupational class. ${ }^{22}$

The increased risk of developing ACPA-positive, but not ACPA-negative RA, among silica-exposed subjects, described in this article, is analogous to the results we obtained among smokers in a previous study, in which citrullinated proteins in alveolar immune cells of smokers were also observed. ${ }^{6}$ Hypothetically, a common feature of silica exposure and smoking may be a link to citrullination of peptides, which when engulfed and presented by antigen-presenting cells may induce an immunological response against citrullinated antigens, which might contribute to the development of RA. ${ }^{635}$ Of interest in this context are the previous observations linking silica exposure to apoptosis, ${ }^{36} 37$ during which citrullination may occur ${ }^{38}$ and to the development of antibodies against apoptotic cells in animal models. ${ }^{39}$ This together with the fact that disturbed apoptosis has been suggested as being a pathogenic factor in smoking-related pulmonary diseases ${ }^{40} 41$ might hypothetically explain some part of the combined effect of silica exposure and smoking, observed in this study. This and other evidence that immunological tolerance against citrullinated proteins/peptides may be broken by exposure of the respiratory tract to exogenous agents, deserves further study.

The results of our study, which suggest an interaction between silica exposure and smoking in the development of ACPApositive RA, underline the importance of considering environmental factors in combination, as well as potential interactions between the environment and genetic polymorphisms in epidemiological studies. These results also provide information about silica exposure and smoking in any discussion about preventive measures against RA, and suggest that smoking potentially interacts with other environmental exposures in the aetiology of the ACPA-positive subset of this disease.

Table 4 Odds ratio (OR) with $95 \% \mathrm{Cl}$ of developing ACPA-positive RA, ACPA-negative RA and RA overall, respectively, among men with different combinations of silica exposure status and HLA-DRB1 'shared epitope' (SE) status, compared with men unexposed to silica who were not carrying SE

\begin{tabular}{|c|c|c|c|c|c|c|c|}
\hline \multirow[b]{2}{*}{ SE status } & \multirow[b]{2}{*}{ Category of RA } & \multicolumn{3}{|c|}{ Subjects unexposed to silica } & \multicolumn{3}{|c|}{ Subjects exposed to silica } \\
\hline & & $\begin{array}{l}\text { Number of } \\
\text { cases/controls }\end{array}$ & $\mathbf{O} \mathbf{R}^{*}$ & $95 \% \mathrm{Cl}$ & $\begin{array}{l}\text { Number of } \\
\text { cases/controls }\end{array}$ & $\mathbf{O} \mathbf{R}^{*}$ & $95 \% \mathrm{Cl}$ \\
\hline \multirow[t]{3}{*}{ No SE } & ACPA-positive RA & $35 / 165$ & 1 & - & $8 / 16$ & 2.51 & 0.97 to 6.49 \\
\hline & ACPA-negative RA & $80 / 165$ & 1 & - & $6 / 16$ & 0.84 & 0.31 to 2.27 \\
\hline & RA overall & $119 / 165$ & 1 & - & $14 / 16$ & 1.32 & 0.61 to 2.86 \\
\hline \multirow[t]{3}{*}{ Any SE } & ACPA-positive RA & $238 / 142$ & 7.86 & 5.10 to 12.12 & $46 / 21$ & 11.39 & 5.10 to 22.07 \\
\hline & ACPA-negative RA & $103 / 142$ & 1.52 & 1.04 to 2.23 & $13 / 21$ & 1.46 & 0.67 to 3.20 \\
\hline & RA overall & $368 / 142$ & 3.54 & 2.59 to 4.83 & $63 / 21$ & 4.45 & 2.53 to 7.83 \\
\hline
\end{tabular}

${ }^{*} \mathrm{OR}$ adjusted for the potential confounding from age and residential area.

ACPA, antibodies against citrullinated peptide antigens; RA, rheumatoid arthritis. 
EIRA Study Group Göran Lindahl, Danderyd Hospital; Berit Sverdrup, Eskilstuna Hospital; Helena Hellström, Falu lasarett; Tomas Weitoft, Gävle Hospital; Bengt Lindell, Kalmar Hospital; Birgitta Nordmark, Johan Bratt and Ingiäld Hafström, Karolinska University Hospital; Ido Leden, Kristianstad Hospital; Björn Löfström, Katrineholm Hospital; Ann Bengtsson and Thomas Skogh, Linköping hospital; Elisabeth Lindqvist, Lund University Hospital; Lennart Jacobsson, Malmö University Hospital; Kjell Huddénius, Rheumatology Clinic in Stockholm City; Christin Lindström, Sophiahemmet; Annika Teleman, Spenshult Hospital; Eva Baecklund and Ann Knight, Uppsala University Hospital; Olle Svernell, Västervik Hospital.

Acknowledgements We would like to express our appreciation to Marie-Louise Serra and Lena Nise for excellent assistance in the collection of data.

Competing interests None.

Funding The study was supported by grants from the Swedish Medical Research Council, from the Swedish Council for Working life and Social Research, from King Gustaf V's 80-year foundation, from the Swedish Rheumatism Association, from Stockholm County Council, from the insurance company AFA and from NIH (P60 AR047782)

Ethics approval This study was conducted with the approval of the regional committee on ethics at Karolinska Institutet, Stockholm, Sweden.

Provenance and peer review Not commissioned; externally peer reviewed.

\section{REFERENCES}

1. Heliövaara M, Aho K, Aromaa A, et al. Smoking and risk of rheumatoid arthritis. J Rheumatol 1993:20:1830-5.

2. Uhlig $\mathbf{T}$, Hagen KB, Kvien TK. Current tobacco smoking, formal education, and the risk of rheumatoid arthritis. J Rheumato/ 1999;26:47-54.

3. Criswell LA, Merlino LA, Cerhan JR, et al. Cigarette smoking and the risk of rheumatoid arthritis among postmenopausal women: results from the lowa Women's Health Study. Am J Med 2002;112:465-71.

4. Stolt $\mathbf{P}$, Bengtsson $C$, Nordmark B, et al. Quantification of the influence of cigarette smoking on rheumatoid arthritis: results from a population based case-control study, using incident cases. Ann Rheum Dis 2003;62:835-41.

5. Padyukov L, Silva C, Stolt P, et al. A gene-environment interaction between smoking and shared epitope genes in HLA-DR provides a high risk of seropositive rheumatoid arthritis. Arthritis Rheum 2004;50:3085-92.

6. Klareskog L, Stolt P, Lundberg K, et al. A new model for an etiology of rheumatoid arthritis: smoking may trigger HLA-DR (shared epitope)-restricted immune reactions to autoantigens modified by citrullination. Arthritis Rheum 2006;54:38-46.

7. Gregersen PK, Silver J, Winchester RJ. The shared epitope hypothesis. An approach to understanding the molecular genetics of susceptibility to rheumatoid arthritis. Arthritis Rheum 1987;30:1205-13

8. Pedersen M, Jacobsen S, Garred P, et al. Strong combined gene-environment effects in anti-cyclic citrullinated peptide-positive rheumatoid arthritis: a nationwide casecontrol study in Denmark. Arthritis Rheum 2007;56:1446-53.

9. Linn-Rasker SP, van der Helm-van Mil AH, van Gaalen FA, et al. Smoking is a risk factor for anti-CCP antibodies only in rheumatoid arthritis patients who carry HLADRB1 shared epitope alleles. Ann Rheum Dis 2006;65:366-71.

10. Michou L, Teixeira VH, Pierlot $\mathrm{C}$, et al. Associations between genetic factors, tobacco smoking and autoantibodies in familial and sporadic rheumatoid arthritis. Ann Rheum Dis 2008;67:466-70.

11. Lee HS, Irigoyen P, Kern M, et al. Interaction between smoking, the shared epitope, and anti-cyclic citrullinated peptide: a mixed picture in three large North American rheumatoid arthritis cohorts. Arthritis Rheum 2007:56:1745-53.

12. National Institute for Occupational Safety and Health. NIOSH Hazard Review: Health effects of occupational exposure to respirable crystalline silica. DHHS Publication Number (NIOSH)2002-129. Cincinnati, OH: US Department of Health and Human Services, CDC, National Institute for Occupational Safety and Health, 2002.

13. Yassin A, Yebesi F, Tingle R. Occupational exposure to crystalline silica dust in the United States, 1988-2003. Environ Health Perspect 2005;113:255-60.

14. Ekman N. Silica in the work environment. The Swedish National Board of Occupational Safety and Health, 1997.
15. Driscoll T, Nelson DI, Steenland K, et al. The global burden of non-malignant respiratory disease due to occupational airborne exposures. Am J Ind Med 2005:48:432-45.

16. Parks CG, Conrad K, Cooper GS. Occupational exposure to crystalline silica and autoimmune disease. Environ Health Perspect 1999;107(Suppl 5):793-802.

17. Turner S, Cherry N. Rheumatoid arthritis in workers exposed to silica in the pottery industry. Occup Environ Med 2000;57:443-7.

18. Steenland K, Sanderson W, Calvert GM. Kidney disease and arthritis in a cohort study of workers exposed to silica. Epidemiology 2001;12:405-12.

19. Stolt P, Källberg H, Lundberg I, et al. Silica exposure is associated with increased risk of developing rheumatoid arthritis: results from the Swedish EIRA study. Ann Rheum Dis 2005;64:582-6.

20. Arnett FC, Edworthy SM, Bloch DA, et al. The American Rheumatism Association 1987 revised criteria for the classification of rheumatoid arthritis. Arthritis Rheum 1988;31:315-24.

21. Klareskog L, Nordmark B, Lindblad S. On the organization of an early arthritis clinic. Best Pract Res Clin Rheumatol 2001;15:1-15.

22. Bengtsson C, Nordmark B, Klareskog L, et al. Socioeconomic status and the risk of developing rheumatoid arthritis: results from the Swedish EIRA study. Ann Rheum Dis 2005; 64:1588-94

23. Bakke B, Stewart P, Eduard W. Determinants of dust exposure in tunnel construction work. Appl Occup Environ Hyg 2002;17:783-96.

24. Guénel P, Breum NO, Lynge E. Exposure to silica dust in the Danish stone industry. Scand J Work Environ Health 1989;15:147-53.

25. Banks D. Silicosis. In: Rosenstock L, Cullen M, Brodkin CA, Redlich CA, eds. Textbook of occupational and environmental medicine. 2nd Ed. Philadelphia: Elsevier, Saunders, 2005:380-92.

26. Rönnelid J, Wick MC, Lampa J, et al. Longitudinal analysis of citrullinated protein/ peptide antibodies (anti-CP) during 5 year follow up in early rheumatoid arthritis: anti-CP status predicts worse disease activity and greater radiological progression. Ann Rheum Dis 2005;64:1744-9.

27. Olerup $\mathbf{0}$, Zetterquist H. HLA-DR typing by PCR amplification with sequence-specific primers (PCR-SSP) in 2 hours: an alternative to serological DR typing in clinical practice including donor-recipient matching in cadaveric transplantation. Tissue Antigens 1992;39:225-35.

28. Miettinen 0. Estimability and estimation in case-referent studies. Am J Epidemiol 1976;103:226-35

29. Rothman KJ, Greenland S, Walker AM. Concepts of interaction. Am J Epidemiol 1980:112:467-70.

30. Rothman KJ. Epidemiology: an introduction. New York: Oxford University Press, 2002

31. Rothman KJ, Greenland S, Lash TL. Modern epidemiology. 3rd Ed. Lippincott Williams \& Wilkins, 2008.

32. Cody RP, Smith JK. Applied statistics and the SAS programming language. 4th Ed. New Jersey: Prentice Hall, 1997

33. Greenberg MI, Waksman J, Curtis J. Silicosis: a review. Dis Mon 2007:53:394-416.

34. Winstanley M, Woodward S, Walker N. Tobacco in Australia: facts and issues. 2nd Ed. Australia: Victorian Smoking and Health Program, 1995. ISBN number: 0646 141031.

35. Klareskog L, Rönnelid J, Lundberg K, et al. Immunity to citrullinated proteins in rheumatoid arthritis. Annu Rev Immunol 2008;26:651-75.

36. Wang L, Bowman L, Lu Y, et al. Essential role of p53 in silica-induced apoptosis. Am J Physiol Lung Cell Mol Physiol 2005;288:L488-96.

37. Hamilton $\mathbf{R F} \mathrm{Jr}$, Thakur SA, Holian A. Silica binding and toxicity in alveolar macrophages. Free Radic Biol Med 2008;44:1246-58.

38. György B, Tóth E, Tarcsa E, et al. Citrullination: a posttranslational modification in health and disease. Int J Biochem Cell Biol 2006;38:1662-77.

39. Pfau JC, Brown JM, Holian A. Silica-exposed mice generate autoantibodies to apoptotic cells. Toxicology 2004;195:167-76.

40. Demedts IK, Demoor T, Bracke KR, et al. Role of apoptosis in the pathogenesis of COPD and pulmonary emphysema. Respir Res 2006; 7:53.

41. Park JW, Ryter SW, Choi AM. Functional significance of apoptosis in chronic obstructive pulmonary disease. COPD 2007:4:347-53. 